\title{
Changes in Congressional Oversight
}

\author{
JOEL D. ABERBACH \\ University of Michigan, and \\ Brookings Institution
}

\section{VARIETIES OF CONGRESSIONAL OVERSIGHT}

Congress has shown increasing concern about oversight as the federal bureaucracy has expanded in size and program initiation has passed to the executive branch. In 1946, following the New Deal and World War II, a provision of the Legislative Reorganization Act prescribed "continuous watchfulness" over the actions of the executive agencies in carrying out the laws. In the 1970 Amendments to the Act, Congress required most committees to issue periodic reports on their oversight endeavors. This was an obvious attempt to spur them to action. Data gathered on congressional oversight in 1973 for the Bolling Committee staff and comments by congressmen before the Committee indicated that this requirement had not produced the desired effect and the House

\footnotetext{
Author's Note: This is a revised version of papers originally prepared for the Commission on the Operation of the Senate and the 1977 Annual Meeting of the American Political Science Association. Generous support from the institute of Public Policy Studies and the Rackham Faculty Development Fund at the University of Michigan and from the Brookings Institution allowed me to recheck the original data analyzed in the Commission and Association papers. Most of the corrections from the rechecking process were entered on the data tape in time for inclusion in this article. The article, therefore, contains some modifications in the dat a reported in earlier papers, although none substantial enough to change any conclusions. Final data reflecting all corrections will be reported as part of my Brookings volume on oversight. I wish to express my thanks to the graduate students at Michigan who assisted so ably in the arduous task of coding, preparing, and analyzing the dat a used here, particularly Celinda Lake and Susan Van Alstyne, and to Cynthia Enquist who did much of the checkcoding while a summer intern at Brookings. Thanks also to Doug Neal of the Bureau of Social Science Research who produced the graphic in Figure I.
} 
amended its rules in an attempt to stimulate more activity and provide some coordination. There is sentiment in the Senate for similar action as indicated by the Interim Report of the Commission on the Operation of the Senate (U.S. Congress, 1976) and by Senate support for "Sunset" legislation in 1978.

When it comes to performance Bibby's (1968) comment that oversight is "Congress' neglected function" is still the standard introductory observation in papers on the subject. The second definition of oversight found in Webster's New Collegiate Dictionary may be unintendedly appropriate: "an overlooking or something overlooked; (an) omission or error due to inadvertence." However, the first meaning, "watchful care or supervision" is surely what we have in mind when we speak about congressional oversight.

There is a debate within the scholarly literature about how to define oversight. Harris proposes a relatively narrow definition. For him, oversight "strictly speaking, refers to review after the fact. It includes inquiries about policies that are or have been in effect, investigations of past administrative actions, and the calling of executive officers to account for their financial transactions" (Harris, 1964). Ogul takes a much broader approach and defines legislative oversight as "behavior by legislators and their staffs, individually or collectively, which results in an impact, intended or not, on bureaucratic behavior," (Ogul, 1976). The Ogul definition is useful in that it directs attention to the fact that oversight is a latent as well as a manifest function of Congress and that many of the things done by Members and Senators contribute to oversight. It is so broad, however, that it is hard to exclude very many congressional activities from inclusion under the oversight rubric. I define oversight as congressional review of the actions of the federal departments, agencies, and commissions and of the programs and policies they administer. This includes review that takes place during program and policy implementation as well as afterwards, but excludes much of what Congress now does when it considers proposals for new programs or even for the expansion of current programs.

As noted above, it is often asserted that Congress neglects oversight. What does occur, with a few exceptions, is said to be neither continuing, comprehensive, nor systematic (Bibby, 1968). Agencies or programs are rarely overseen persistently, the focus of the oversight effort is often very narrow, and it is certainly the case that systematic oversight efforts (those involving a methodical approach governed by some rational principle which orders and gives unity to the elements of the effort) are just about impossible to uncover. 
A basic assumption underlying much of the normative discussion in this article is that, simply stated, oversight of administration is desirable because it provides one mechanism by which those who administer the public policies which singly or cumulatively affect us in fundamental ways can be held accountable and their programs evaluated. I also assume that more oversight is usually better than less. ${ }^{1}$ The idea behind this is quite simple: even oversight performed sporadically, focused on fairly narrow subjects, and utilizing an unsystematic approach should at least hold down flagrant abuses of power by administrators, make them more responsive to the wishes of Congress, and provide Members and Senators with better knowledge and use in making judgments about the effectiveness of programs. Persistent oversight of programs or agencies is, I assume, more likely to yield these benefits than random reviews, but the benefits of regular efforts in an area may not be commensurate with the high costs in time and effort involved unless the quality of the oversight is improved. ${ }^{2}$ And quality can only be significantly improved through efforts to evaluate programs in a comprehensive and systematic manner. Great difficulties are suggested by the latter point because our political system diffuses authority and promotes legislation which often enumerates unclear and even contradictory goals for programs.

The issue, then, is how to promote more and better oversight. Separating the elements of quantity and quality is, of course, a simplifying device. If one accepts it, a futher simplification will aid us in the analysis. This involves a division of the factors often thought to promote oversight into those whose effect is mainly to increase the quantity (incidence) of oversight and those which are very likely also to increase the quality of oversight. A further distinction, given our interest in change, will be drawn between those factors which are subject to planned manipulation (i.e., can be affected through policy changes) and those which are basically beyond our control.

\section{FACTORS MAINLY PROMOTING A GREATER INCIDENCE OF OVERSIGHT}

The literature is filled with propositions about factors which promote oversight. ${ }^{3}$ A good number seem mainly to affect the quantity of oversight done. the following is a brief enumeration of some of these factors plus some commentary where appropriate:

(1) Split partisan control of the presidency and Congress. If different parties control the presidency and Congress, the majority in Congress 
has an incentive to harass and embarrass the executive for partisan gain. This is not a factor which is conducive to persistent oversight of a policy or agency and it is not something which we can control. However, there is one reform which has been suggested which would produce much the same stimulus to oversight and would always be as effective as split control; that is to give the minority party in Congress (if it does not also control the presidency) control of the Government Operations Committees and of oversight subcommittees of the authorization committees.

(2) Casework problems. If the bureaucracy is unresponsive to requests for assistance for the constituents of a strategically placed Senator or Representative (i.e., a committee or subcommittee chairman or ranking members, and the like), the oversight may be used as a means to set things aright. One would not expect this to happen very often or to require persistent oversight to correct the situation.

Casework problems are not something we can manipulate in the interest of increased oversight, but there might be a way to use casework information to stimulate oversight and perhaps improve its quality as well. Congress could establish a central office to collect and analyze information on casework requests and responses to them. A periodic report which highlighted recurrent problems might create pressure for (and information to be used in) a review of the agencies or programs involved.

(3) Attempts to satisfy group interests important to the Senator or Congressman. This is a broader category than two, but shares much in common with it. Most established interests are well represented in the bureaucracy; program administrators wish to provide them with services, and administrators are especially responsive to those groups of concern to important people in Congress. Every once in a while, however, vocal dissatisfied groups stimulate spurts of oversight as in the case of OSHA (Occupational Safety and Health Administration).

(4) Desire to protect favored agencies. This factor is related to (3), only here the Senators and Congressmen are mobilized by bureaucrats as well as interest groups to protect a program which is threatened by the administration or which needs a boost for some other reason. The purpose of the oversight effort is to show how marvelous or essential 
the program is and to demonstrate the depth of its support. Such efforts, I believe, are especially common when there is split partisan control of the Congress and the presidency, but probably occur at all times. "Sunset" laws of the type now under consideration in Congress would unintentionally stimulate this type of oversight on a regular schedule. While protective oversight is likely to be very superficial, every once in a while it will expose flaws in a program which even its most ardent supporter will want to see corrected.

(4a) Efforts to preempt opponents. Preemptive oversight is really a special case of protective oversight. As Scher says, some oversight (which he terms preventive) "results from an unenthusiastic determination that a limited examination of an agency by its friends may cost less than an uncontrolled one by its enemies" (Scher, 1963). Such oversight is likely to be superficial and brief, but the incentive to perform it is subject to some manipulation. A restructuring of committee jurisdictions which encouraged "unfriendly" committees to take a look at the program or agency in question would encourage this type of oversight. The new budget process may be a particularly important stimulus to preemptive oversight since authorization committees will want to present what looks like a strong case to the Budget Committees. I will return to this point later in describing factors leading to higher quality oversight (because should the budget process really work it is likely that superficial evaluations will be at a disadvantage in competition with more systematic efforts).

(5) Committee structure. We now turn to a factor which is very much subject to planned manipulation: committee structure. The more decentralized the committee, the greater the likelihood of oversight. As Ogul (1976) notes, "a decentralized committee-one in which power over money, staff, and program is largely in the hands of subcommittee chairmen and others-enhances the opportunity for oversight simply because decision-making is dispersed."

An additional factor which ought to lead to a greater incidence of oversight is the establishment of oversight subcommittees. Once established, many members of these subcommittees and their staffs should want to make something of their assignments and greater oversight activity is a likely result. 
(6) Increasing staff resources. The latter point raises the general issue of staff resources. One would expect that increases in the number of staff members on committees and subcommittees and increases in staff assigned to individuals both in their offices and through their committee assignments would lead to more oversight activity. There would probably not be a one to one relationship between the number of staff and oversight, but one would expect some impact if only because of the greater number of people available to do things. However, when authority over staff is dispersed, increases in the number of staff are more likely to lead to increases in the level of oversight activity than to increases in systematic oversight. The problems of lack of coordination and lack of an orderly, methodical approach to oversight are, in fact, probably exacerbated by mere increases in the numbers of staff aides.

(7) Corruption, crisis, and publicity. Evidence of corruption, the breakdown of a program, or the subversion of accepted governmental processes as revealed by Watergate make oversight attractive because the overseer is almost sure to make a favorable public impression. Most such oversight is not planned for in advance and is likely to be shortlived and somewhat superficial. But Watergate and the feeling that the Great Society programs of the 1960s were ineffective may well have had a profound impact on both the attentive public and the people in Congress themselves, alerting them to the need for "continuous watchfulness."

A related factor which may bring Congressmen who oversee the executive branch publicity previously unavailable is the rise of citizens' lobbies with wide memberships or favorable public recognition. These groups place oversight of target agencies and programs on their agendas and publicize congressional response. They also are sources of information previously unavailable. They seem to be a stimulus to more oversight, but whether they will sustain themselves through time or maintain a steady enough interest in an area to reward persistent congressional attention is not yet clear.

\section{FACTORS LIKELY TO INCREASE THE QUALITY OF OVERSIGHT}

The analysis in the preceding section was inspired by recent academic work (especially Scher, 1963; Ogul, 1976) that approaches oversight from the perspective of the incentives of the Senators and Representa- 
tives. While more traditional scholars spend much time examining the techniques of oversight (hearings, investigations, and so on) and the resources available (staff, money, and so on), Scher and Ogul ask what net gains accrue to Senators and Representatives from performing oversight. Investigations, to take one example, can yield great publicity dividends if they expose corruption or harass unpopular agencies, but they may prove politically useless or even damaging if they turn up nothing newsworthy or threaten powerful interests. Persistent oversight of an agency or program is even more time-consuming than a one-shot investigation and the publicity rewards are likely to be much lower. In brief, when the disadvantages outweigh the advantages one assumes that Congressmen and Senators shy away from oversight, even though they may believe that it ought to be done.

When one looks at oversight in this way it is not surprising that performance has usually been spotty at best, with persistent oversight a rarity and really thorough systematic jobs almost nonexistent. However, over the last few years there have been changes in the environment which ought to make improvement in the quality of oversight more attractive to many in Congress. This certainly does not guarantee that such improvements will occur, but it does make it more than an academic exercise to discuss factors likely to increase the quality of oversight.

(1) Relative resource scarcity. Many of us are accustomed to thinking about an ever-growing economy with rapidly increasing resources available to government for the expansion of old programs and the establishment of new ones. This environment discourages the careful oversight of ongoing programs which usually have the support of entrenched constituencies. There is no pressing reason to worry much about efficiency or effectiveness in such an environment and, therefore, little oversight should be expected, let alone systematic oversight.

We are now in a period of relative resource scarcity. In addition to the strains brought on by the recent recession, many of the programs of the 1960 s proved much more expensive than originally estimated. Together with the belief that many government programs are not working very well, these factors have created a growing interest in the attentive public in efforts to determine the effectiveness of programs and to weigh them against possible alternate uses of the resources they consume. There is a growing constituency which supports such efforts and public acclaim to be gained by backing them. In addition, if hard 
choices must be made, the political costs may be reduced by transferring responsibility for unpopular decisions, i.e., fixing the blame on the outcome of carefully conducted, technically respectable analyses. In short, relative resource scarcity has created a political climate which makes high quality, systematic oversight more attractive than it was before.

(2) Influx of skeptical Senators and Representatives. Contributing to this climate is the influx into Congress of Democrats described by Representative Bob Carr as "skeptical of government intervention and solutions." (Singer, 1978) Their electoral success reinforces the belief that a skeptical view is popular with the public and may advance the notion that thorough, systematic oversight can yield some political payoff.

(3) Widespread program evaluation. In part as a consequence of the relative scarcity of resources described above, in part as a reflection of the spread of new analytic techniques, and in part as a function of new mandates given to the executive agencies, congressional support agencies, and congressional committees themselves, program evaluation is being done all over the government. It is not always well done and it is often self-serving, but it does put pressure on Congress to examine the findings and at least to consider the results.

A major problem is that low quality evaluations are encouraged by the types of programs Congress typically passes. In order to build a coalition large enough to pass a bill and in an effort to offend as few people as possible, Congress often establishes programs which lack clear, noncontradictory goals for the agencies to accomplish.

Schick (1976), however, notes that

when Congress muddles through without a clear specification of purpose, the process of evaluation is not aborted. Rather, it must begin with executive implementation rather than with text book clarity about objectives. Congress, in fact, has two legitimate tasks to get the Executive to produce relevant evaluations. First, Congress can write into law a mandate for the agency to evaluate its program; second, Congress can demand that the evaluative measures used by the agency reflect congressional interest and perspectives, not merely the orientation of the implementing agency. ... What is required is the prescription in law of a process that agencies must adhere to in evaluating their activities, including milestones for the crucial events in the process, and a reporting schedule.

Schick's proposals are realistic and would improve the prospects for the intelligent utilization of program evaluations by Congress. They 
suggest a general point which is that congressional committees should work closely with any agency (for example, GAO) doing evaluations for them - or the products are unlikely to have much impact. The process Schick proposes will not eliminate all muddled program objectives and the problems they create (it does, after all, involve continuous bargaining between Congress and the agencies) and it will not result in high quality program evaluations as measured by a set of absolute professional standards, but it will increase the usefulness and impact of the evaluations done.

Effective congressional utilization of evaluation requires the active interest of Senators and Representatives, staff members who can skillfully direct the work of technical experts, and a congressional willingness to bite the bullet at times when evaluation results cause some political difficulties. No one can mandate such things, but changes in the political climate and in the composition of Congress give some encouragement that this might be possible.

It would be helpful, in this regard, to develop courses in evaluation for politically skilled but analytically untrained staff. This would help facilitate fruitful communication between Congress and evaluators from the congressional support agencies or the executive departments.

(4) Reforms in the budget process. The most important potential stimulus to systematic oversight by the Congress is the new budget process established by the 1974 Budget Act. As Schick notes (1976):

\footnotetext{
there is some possibility that the new congressional budget process might bolster the incentives for evaluation at [the authorization and appropriations] stages, if only because of the pressure to consider particular spending demands in the light of overall national priorities and other claims on the budget. Moreover, the new congressional process might contribute to a narrowing of the authorizationsappropriations gap, the proclivity to authorize one level of expenditure but to appropriate at a much lower level. More realistic authorizations might encourage committees to take more careful looks at the programs subject to their oversight.
}

A possible scenario is that some presentations to the Budget Committees by the authorization committees of their views and recommendations on matters to be covered in the budget resolutions (as required in Section 301(c) of the Act) will be based on evaluations designed to make favored agencies and programs look good. ("Preemptive oversight" may also take hold here-a desire to evaluate programs before $\mathrm{CBO}$ or the Budget Committee staffs get to them.) With any luck, some authorization committees will seek to influence the Budget Committee by present- 
ing more systematic evaluation than those of the competition in order to back up their claims to the available funds. The Budget Committees, if they reward such efforts, can thereby stimulate a continuing improvement in the quality of oversight.

(5) Rotation of committee memberships. A final factor which might increase the quality of oversight would be the regular rotation of committee assignments. Such a procedure could have several benefits. First, it would loosen the ties which Senators and Representatives develop with the agencies whose programs their committees authorize or fund. This, in itself, would be a stimulus to more objective perspectives on programs and the agencies which administer them. Second, by moving from committee to committee, each individual might develop a better view of the overall situation. Third, because of the need to develop a quick comprehension of the agencies and programs involved, the Senators and Representatives might be more interested in seeing thorough studies of relevant policies, especially studies which compared benefits across programs or agencies.

The difficulties with this proposal are many, but two (leaving aside resistance to change) stand out. First, unless the staff attached to the committees had low turnover, committees would be even more reliant on the executive for information and expertise than they are now. Second, if the staffs remained in place, the perspectives of program clientele groups and the agencies might still dominate the process. Reserving some staff positions for people whose professional training is in policy analysis might help here.

\section{AN ANALYSIS OF TRENDS IN CONGRESSIONAL COMMITTEE OVERSIGHT BEHAVIOR}

As I indicated earlier, the notion that oversight is Congress's neglected function is widespread, shared alike by scholars and legislators. The survey of oversight activity by House Committees done by the Congressional Research Service for the Bolling Committee (1974), for example, showed that $11 \%$ of all hearing and meeting days in the first eight months of the Ninety-Third Congress (January 1 to September 5, 1973) were devoted to oversight. ${ }^{4}$ The prevailing inference drawn from these data was that $11 \%$ was too low a number. Thus, the Committee's report expressed a firm belief that "the oversight responsibilities of the 
House Committees are important and too often shunted aside by the press of other business" and endorsed the view "that oversight of programs and agencies should be a principal function of the Congress." The significance of the $11 \%$ figure will be considered below in my examination of oversight activity over the last four Congresses.

This part of my article documents and provides some preliminary analysis of trends in congressional oversight behavior. The analysis is longitudinal, covering the Ninety-First, Ninety-Second, Ninety-Third, and Ninety-Fourth Congresses, and comparative, contrasting the House and the Senate. The analysis has two major purposes:

(1) to document the amount of oversight behavior in committee hearings and meetings for each of the last four Congresses;

(2) to perform a preliminary analysis of the impact of some of the factors identified earlier as likely to promote a greater incidence of oversight.

The nature of the data I employ here requires me to place my major emphasis on the quantity of oversight, but I will also briefly consider the implications of the evidence for the quality of the oversight being done.

My data source is the Daily Digest which is appended to the Congressional Record. The Daily Digest lists and summarizes the meetings and hearings held by congressional committees. The time period coded for each Congress is January 1 to July 4 of the first year of each session, i.e., $1969,1971,1973$, and 1975. The unit of analysis is a hearing and/or meeting series dealing with what I call a "matter," defined as a subject, theme, or topic. The coders were instructed to code as a unit a series of hearings and/or meetings on one subject, topic, or theme. The number of days of hearings and / or meetings per matter was also recorded so that the total amount of time spent on each matter can be recovered from the data where that is desirable.

All hearings or meetings listed in the Daily Digest were coded so that effort spent on oversight as measured from this source could be compared to activities devoted to other purposes such as authorizations, nominations, and so on. Oversight is defined here conceptually as congressional review of the actions of the executive branch and operationally as hearings or meetings held for any of the following purposes, either singly or in combination: (1) to review and/or control unacceptable forms of bureaucratic behavior; (2) to ensure that the bureaucracy implements the policy objectives of Congress; and (3) to determine the 
effectiveness of programs and policies. In addition committee hearings or meetings described in less precise terms than those above simply as efforts to review or oversee the activities of an agency were coded as oversight. The numbered elements of the operational definition were drawn from the CRS study for the Bolling Committee (U.S. Congress, 1974: 267). The difference between their study and mine is that I did not code as oversight hearings or meetings designed, in their words, "to analyze national (and international) problems requiring Federal action" unless they were part of an effort to review government actions in the area.

Before proceeding, I should note some of the shortcomings of the data set. First of all, it understates the amount of committee activity to some extent because the descriptions in the Daily Digest are inserted by the Committees themselves. If for any reason they fail to submit copy to the Record, there is no entry for any hearings or meetings they may have held. Second, the descriptions submitted are not always as clear as one might hope. We guarded against error by double-coding any questionable entries in the Digest. Third, the data are records of hearings and meetings, not other activities of the committees. They, therefore, do not necessarily include such efforts as staff investigations and the like which can be important aspects of oversight, unless those efforts are reflected in hearings and meetings. Finally, oversight may occur as a byproduct of hearings and meetings held by congressional committees for other purposes. Accordingly, the data analyzed in this article underestimate the amount of oversight because they consider only the primary purpose of each hearing or meeting as described in the Daily Digest.

\section{CHANGES IN COMMITTEE OVERSIGHT ACTIVITY}

Most congressional committees are quite busy and the evidence indicates that the number of hearings and meetings held by them has increased significantly since 1969 , the first year coded in our data set. Table 1 presents the number of hearings and/or meetings series coded in each of the four Congresses, the total number of days spent in hearings and meetings, and the mean days per series for all House and Senate committees except Appropriations, Rules, and Administration. 5 The committees dealing with rules and administration were excluded from the analysis because of their preoccupation with internal chamber business. The appropriations committees were excluded for reasons of 
TABLE 1

Frequency of Committee or Subcommittee Hearings and Meetings in the House and Senate, by Congress

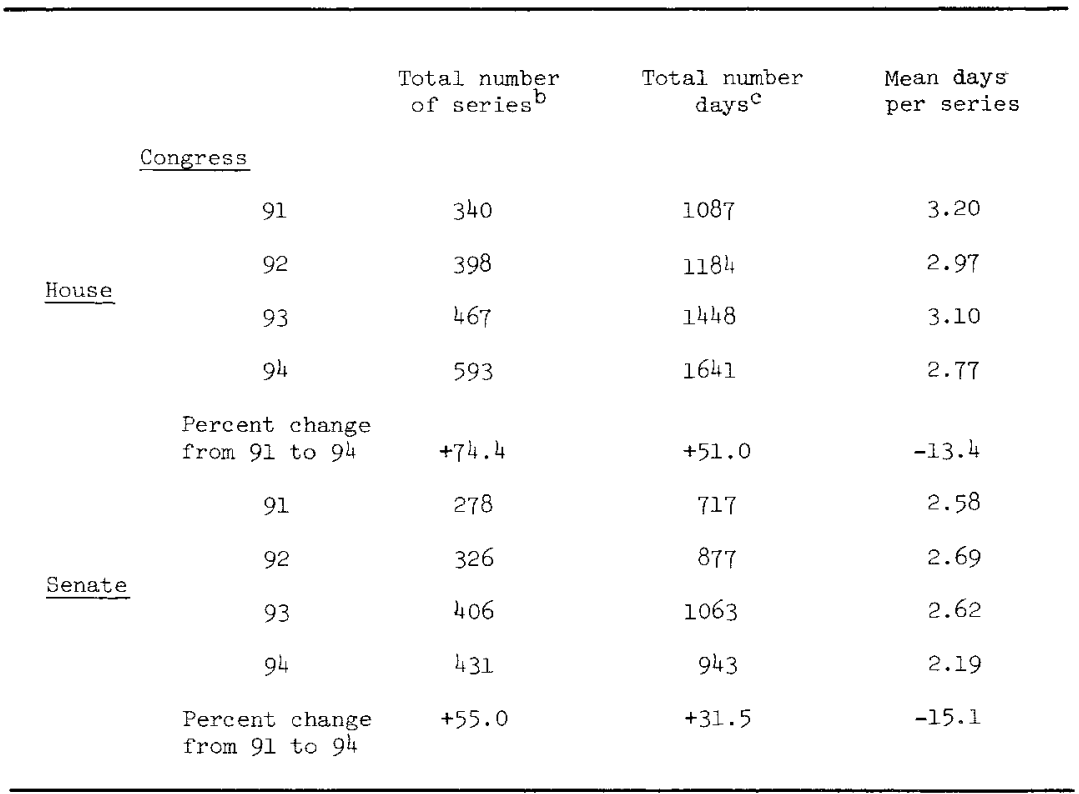

NOTE: Entries are for the January 1 to July 4 period of the first year of each session of the Ninety-First to Ninety-Fourth Congresses.

a. Hearings and meetings held by the Appropriations, Rules, and Administration committees in each chamber have been excluded.

b. A series is defined as a set of hearings and/or meetings on one subject, topic, or theme. c. The total number of days is derived by adding the number of days of hearings and/or meetings in each series.

comparability since the House Committee followed its unique tradition until the Ninety-Third Congress of reporting very few of its hearings or meetings for inclusion in the Daily Digest.

The total number of hearings and meetings series increased rapidly in both the House and the Senate in this period. The Senate workload shows some signs of leveling off in the Ninety-Fourth Congress (there was a dip in the total days column from the Ninety-Third), perhaps indicating a rough saturation point in the area of 1,000 hearings or meetings in a six-month period for the Senate committees coded here. What is clear is that committees in both bodies meet even more often than they did just a few years ago and that more and more matters are taken up in each session. ${ }^{6}$ 
Table 2, which displays data on oversight hearings and meetings, shows a fairly consistent pattern of increases both in the number of series and in the total days devoted to oversight. The one exception is found in the House where the number of oversight series decreased slightly from the Ninety-First to the Ninety-Second Congress while the total number of oversight days dropped rather precipitously. This relatively steep drop in the number of days devoted to oversight is a function of a drop in the mean number of days spent on oversight per series. As the change from a standard deviation of 5.55 in the House in the NinetyFirst Congress to 2.40 indicates, there were fewer extreme cases in the Ninety-Second Congress. In fact, one oversight series of 33 days of hearings and meetings in the Ninety-First Congress is the culprit. This was the largest series by far, the next longest oversight series recorded in the period covered by the data being 16 days long. At any rate, with the one exception described, oversight not only increased in absolute terms from Congress to Congress, but it held its own as a percentage of a rapidly increasing committee workload. It began to rise in the House in the Ninety-Third Congress as a percentage of total series of hearings and meetings and in the Ninety-Fourth Congress exploded into prominence in both chambers as a major percentage both of series and of hearings and meeting days.

How does one explain this change in congressional oversight behavior? Earlier, I outlined a group of factors which have been identified as promoting a greater incidence of oversight. Split partisan control of the presidency and Congress has been a constant factor in the period covered by the analysis and unfortunately, therefore, its direct impact on oversight activity cannot be assessed using these data. ${ }^{7}$ In addition, the data, because of limited information in the Daily Digest, are not appropriate to answer questions about the relationship between oversight activity and such factors as casework problems, attempts to satisfy group interests important to the Senator or Congressman, or the desire to protect favored agencies. Additional analytic work could be done in these areas by evaluating hearings transcripts and interviewing participants. However, the data collection problem will be a difficult one since the investigator would ideally like to know not only what motivated a given instance of oversight activity, but when similar conditions (casework problems and the like) existed and no oversight resulted.

Fortunately, there are some data presently available which can help to probe the relationships between the remainder of the factors identified earlier and oversight activity. Turning first to staff resources, it 
TABLE 2

Oversight Hearings and Meetings by House and Senate Committees or Subcommittees, by Congress

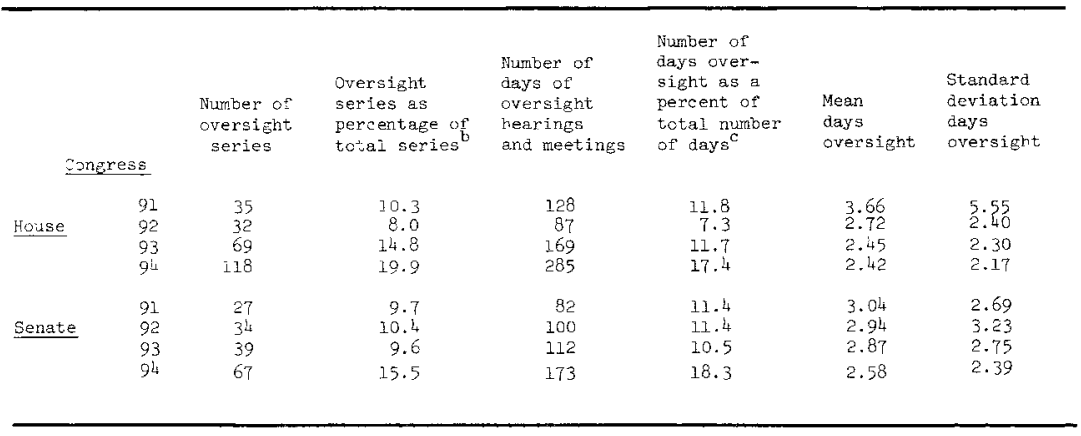

NOTE: Entries are for the January 1 to July 4 period of the first year of each session of the Ninety-First to Ninety-Fourth Congresses.

a. Hearings and meetings held by the Appropriations, Rules, and Administration Committees in each chamber have been excluded.

b. See Table 1 for a count of the total number of series.

c. See Table 1 for a count of the total number of days.

was hypothesized that oversight would increase as a function of the number of staff available to committees and subcommittees. Information collected by the Temporary Select Committee to Study the Senate Committee System on numbers of staff members available to House and Senate Committees is the basis of the rather remarkable plot found in Figure 1. The horizontal axis is the total number of permanent, inquiries and investigation staff available in 1969, 1971, 1973, and 1975 to all Senate Committees as reported by the Temporary Select Committee (1976) and the vertical axis is the total number of days Senate Committees spent on oversight in those years. The total number of days Senate Committees spent on oversight during this period appears to bear an almost linear relationship to the total staff available.

Before declaring increases in staff the definitive factor promoting more oversight, a few cautions are in order. First of all, Figure 1 covers a very short time span and chance may be at work here. The data might not be quite so neat if a longer series could be examined. ${ }^{8}$ Second, while complete data on staff growth for the House are not available, the data for 1969 and 1971 which are presented by the Temporary Select Committee present a problem. Staff in the House grew from 688 to 799 in this period, while a look at Table 2 will show that total days of oversight in the House fell during this same time span. Perhaps the relationship 
between staff and oversight only exists in the Senate, but one would want to see more data on both chambers before reaching that conclusion. Third, correlation does not indicate causation and in the case of these variables the direction of causality is not absolutely clear. More staff may be promoting oversight, but the reverse may also be true and the desire of Senators to oversee the bureaucracy may be leading them to hire more staff. If the latter is correct, when and if the desire abates, staff increases may well be associated with constant or even decreasing levels of oversight. ${ }^{9}$ My own feeling on this point is that the system is a complex one in which additional people are slack resources some of whom find their way into oversight activity regardless of the priorities of their employers, but the key point for now is that one should be cautious in interpreting these data.

Next, let us examine the committee structure factor. This factor is an extremely important one for those interested in reform because, like the staff factor, it is very much subject to planned manipulation.

Two propositions were outlined earlier. The first is that the more decentralized the committee, the greater the likelihood of oversight. In order to make a satisfactory test of this proposition one would want to develop good measures of the dispersal of power over money, staff, and the agenda in each committee and then relate them to the level of oversight activity. Such measures are not currently available, but one crude indicator of decentralization - the number of subcommittees on the full committee ${ }^{10}$-does not show very promising results. The average correlation between the number of subcommittees and the amount of oversight conducted (the oversight indicator was coded here as a dummy variable, i.e., $1=$ oversight and $0=$ other) is .05 in the House and .01 in the Senate for the four Congresses in the data set. In addition, the correlations in the House for the Ninety-Third and Ninety-Fourth Congresses, those after the passage of the so-called "Subcommittee Bill of Rights" (Ornstein, 1975), were -.02 and .05 , respectively.

The second proposition on committee structure outlined above, namely that the establishment of oversight committees or subcommittees is likely to lead to an increase in oversight activity, seems very promising. These units would have oversight as a major mandate and the assumption is that if they are active at all they will be more likely than other units to devote their efforts to overseeing the executive. Fortunately, it is fairly easy to identify existing oversight committees and subcommittees (which we will call oversight units) and to compare their behavior to that of nonoversight units. 


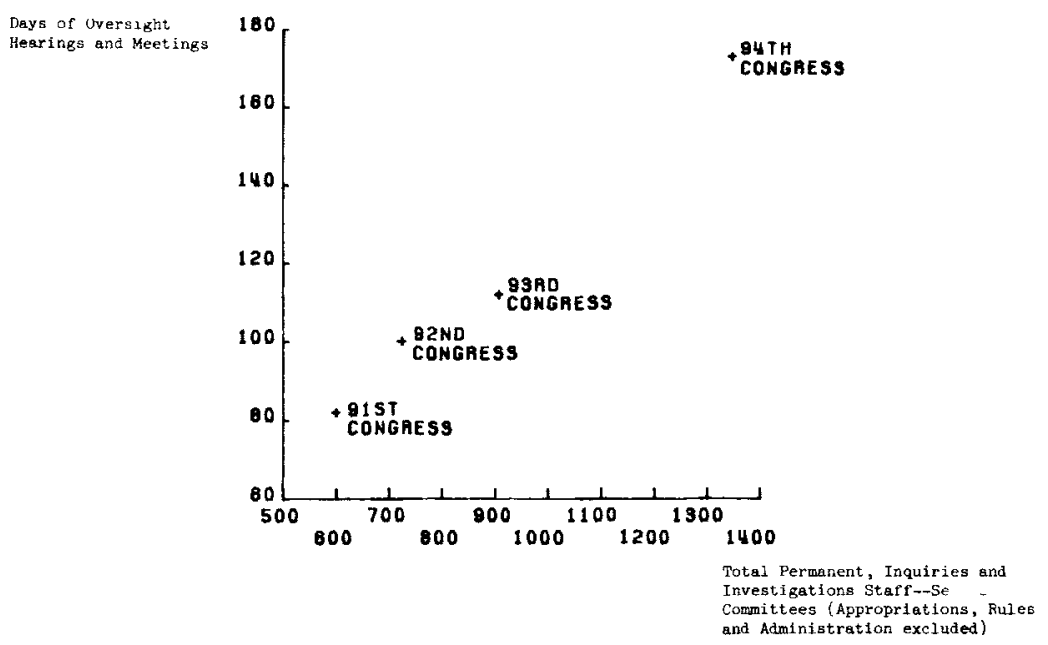

NOTE: Oversight entries are for the January 1 to July 4 period of the first year of each session of the Ninety-First to Ninety-Fourth Congresses.

Figure 1: Staff Size Versus Days of Oversight Hearings and Meetings, Senate

In Table 3 the percentages of hearings and meetings series devoted to oversight are presented both for oversight units and for the remainder of the committees and subcommittees. The data are further divided by chamber and Congress. Oversight units are defined as the Government Operations Committees in both chambers and subcommittees of other committees which have such identifying labels as oversight and department operations in their titles.

A look at the table will show some very clear findings in the House. Oversight units do indeed devote more series of hearings and meetings to oversight than other committee units. The differences are quite pronounced. Indeed, the average correlation ( $r$ ) between dummy variables for the oversight and committee units indicators is .28."1

Both oversight and nonoversight units have increased their oversight percentages since the Ninety-First Congress. However, the House oversight units' share of the total oversight series, i.e., the percentage of the total oversight series in each Congress which they conducted, has dropped from $37.1 \%$ in the January 1 to July 4 period of 1969 (the Ninety-First Congress) to $30.5 \%$ in the comparable period of 1975 
(the Ninety-Fourth Congress). ${ }^{12}$ This drop resulted from the fact that the percentages of series devoted to oversight rose more steeply for the nonoversight than for the oversight units. The difference in oversight percentage growth rates was enough to overcome the greater percentage increase in the number of series held by the oversight units.

In the end, then, one must conclude both that the oversight units on the House committees do spend a higher proportion of their time on oversight series than the nonoversight units and that the large increase in oversight found in the House cannot be accounted for simply by the increase in activities of the oversight units. What has happened is that most everyone is now getting into the act in a bigger way than before. Before discussing a factor which may have contributed to this substantial increase in oversight effort, let me say a few words about the data on oversight units in the Senate.

The Senate data on the percentages of series devoted to oversight by oversight committee units resembles that found in the House (i.e., much higher percentages) only in the Ninety-Fourth Congress. One wonders why there are virtually no differences for any of the other Congresses. The main reason is that in the Ninety-First, Ninety-Second, and NinetyThird Congresses the Senate Government Operations Committee was the only oversight unit which held any hearings or meetings at all. (In fact, it was the only one in existence in the Senate.) This is important because the Government Operations Committee, unlike most of the oversight subcommittee units, has a firm legislative mandate and, therefore, is likely to be occupied with tasks other than oversight. ${ }^{13}$ The committee, for instance, was very busy during much of the period before the Ninety-Fourth Congress shaping complex legislation such as the Budget and Impoundment Control Act. Only in the Ninety-Fourth Congress do oversight units from Senate committees other than Government Operations begin to appear in the data. I am reluctant, therefore, to reach any firm conclusions about the effectiveness or ineffectiveness of Senate oversight units in producing actual oversight activity. Before reaching such conclusions, I would wait until there are a few more oversight subcommittee on regular Senate authorization committees and then examine their behavior.

There is one final factor discussed above which is said to make oversight more attractive to legislators. The relationship between that factor, labeled "corruption, crisis and publicity," and increases in oversight is not the easiest to establish, but Watergate, which was a mixture of all three seems to have had a clear impact. As Table 2 demonstrated, 


\section{TABLE 3}

\section{Percentages of House and Senate Hearings and Meetings Series Devoted to Oversight, by Committee Unit and Congress}

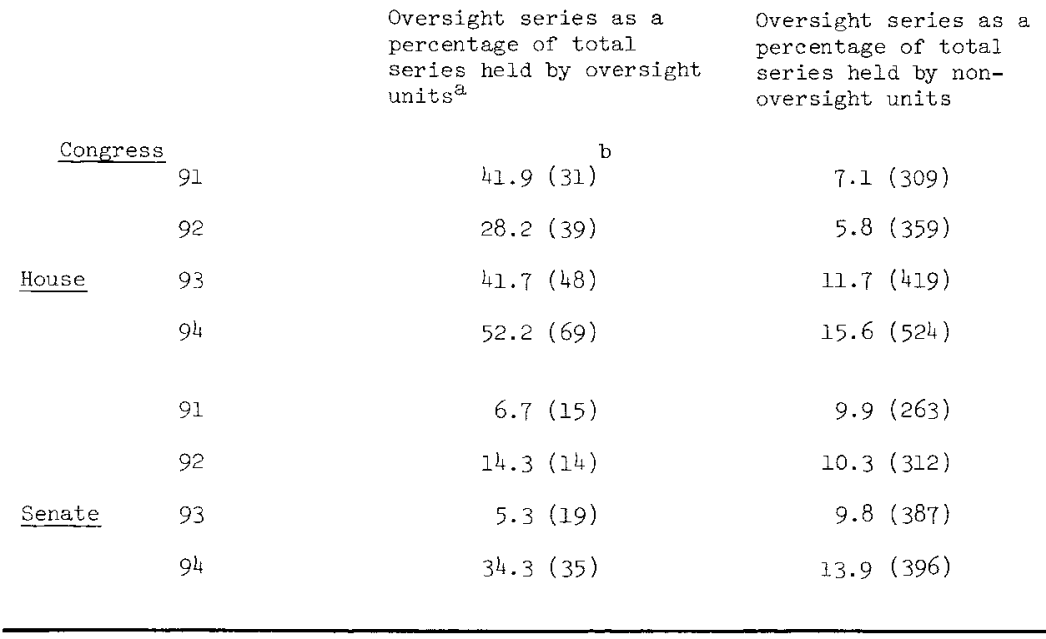

NOTE: Entries are for the January 1 to July 4 period of the first year of each session of the Ninety-First to Ninety-Fourth Congresses.

a. Oversight committee units are defined as the Government Operations Committees in both chambers and subcommittees of other committees which have such identifying labels as oversight and department operations in their titles. Hearings and meetings held by the Appropriations, Rules, and Administration Committees in each chamber have been excluded.

b. Ns in parentheses are the bases upon which percentages are calculated.

the absolute number of oversight series and days generally increased during the period of the Ninety-First to Ninety-Fourth Congresses, but oversight really jumped into prominence as a major percentage of the daily activities of House and Senate committees in the post-Watergate (Ninety-Fourth) Congress. While other factors are surely important, it is highly unlikely that the juxtaposition of the Watergate crisis and the literal explosion of oversight is mere coincidence.

\section{CONCLUDING COMMENTS}

The very rapid recent growth in oversight may well be a temporary phenomenon-a fad inspired by the political currents flowing from Water- 
gate. There is certainly a faddish element to it at the moment and the level of oversight activity may well fade soon. However, there are reasons to think that a fairly solid foundation for substantial oversight activity does exist (although not necessarily at the very high levels found in the Ninety-Fourth Congress) and the data developed in this study indicate some factors which can be manipulated in an effort to maintain a high incidence of oversight activity by congressional committees.

The whole Nixon period brought into focus a growing imbalance of power between the executive and legislative branches. As the data show, congressional activity increased rather dramatically from the NinetyFirst to the Ninety-Third Congress. Yet during this time oversight held its own as a percentage of this growing activity, dipping only in the House in the Ninety-Second Congress and recovering quickly in the Ninety-Third Congress, a time when oversight reforms were an important item on the Bolling Committee agenda. Watergate may well have been the chief factor leading to the dramatic increase in oversight recorded in the Ninety-Fourth Congress, but there was already a substantial and growing base of oversight activity prior to that time. I suspect that the pre-Watergate increase in oversight activity derived from the suspicion of presidential power which developed in the Johnson Administration mainly as a result of the Vietnam war and on a widespread disillusionment with many of the programs of the $1960 \mathrm{~s}$. Even during Nixon's first term Congress attempted to place limits on presidential war and spreading powers and initiated serious debate on program priorities. Oversight tended to increase as a natural concomitant of these efforts (and related changes in congressional rules and resources), and as a response to a growing attentive public which showed an interest in congressional efforts to control the executive branch. My argument, in essence, is that Watergate stimulated oversight activity, but that it occurred in a context of related stimuli and reinforced them. If this is so, one would expect the observed increases in oversight activity to persist-although perhaps not at quite such high levels --even as memories of Watergate per se recede.

Turning now to factors which the data suggest might be manipulated to encourage oversight, two stand out: increased committee staffs and the establishment of more oversight units. On the first, some cautions against too simple an interpretation of the data are expressed in the article, but the evidence does at least suggest that increasing committee staff resources has an impact on oversight activity. As noted, the impact is probably less dramatic than a first glance at Figure 1 would lead one 
to think. However, even if one believes merely that some new staff people will haphazardly find their way into oversight, then further increases in staff will help maintain or even increase oversight activity. Staff earmarked for oversight duty are even more likely to have this effect, though one would realistically expect much slippage between the duties they are supposed to perform and their actual assignments.

The second factor, oversight units, potentially is important not because it is likely to increase oversight activity greatly, but because of its potential as a backstop. The data indicate that oversight units, particularly oversight subcommittees without major legislative authority, do spend a much higher proportion of their time in oversight activities than nonoversight units. They were by no means the major factor responsible for the increases in oversight activity reported in the data, but the empanelling of more oversight subcommittees should establish a base for a higher minimum level of oversight in the Congress.

In closing, let me say a few words about some priorities for future research. First, research of the type reported here will benefit from a longer time frame, particularly in terms of establishing a norm for oversight in the pre-Nixon years, testing the import of split partisan control, and gaining a better understanding of the relationship between committee staff size and oversight behavior. Second, oversight sometimes occurs in hearings and meetings held primarily for some other purpose such as authorizing or appropriating money for ongoing programs. A more comprehensive study design would take this fact into account through such means as content analysis of hearing and meeting transcripts and interviews with participants. It also would consider oversight which occurred outside of the formal hearing or meeting framework. Third, much more work needs to be done on the quality issue. Case studies of various types of oversight efforts probably would be the best way to begin to understand better the conditions leading to more comprehensive and systematic oversight. Finally, not enough is known about the impact of oversight activity on the actions of administrators. Just what effects does oversight really have? An assumption was made at the beginning of the study that more oversight, even if it is not comprehensive or systematic, is better than less because of its likely impact on administrators' behavior. This assumption, while plausible, is so central to making decisions about reforms aimed at increasing the quantity of oversight that we should find out all we possibly can about its validity. 


\section{NOTES}

1. I use the adverb usually because oversight can be performed in a terribly destructive manner if Congress does not exercise a minimum level of self-restraint. The prime example is the McCarthy "investigation" of government personnel practices in the 1950s.

2. There are certainly benefits to be gained from reviewing a program in a persistent yet unsystematic manner. However, the major payoff from either sporadic or regular unsystematic oversight probably comes from the anticipation by the administrators that the overseers just might uncover something embarrassing.

3. See, especially Scher (1963), Ogul (1976) and Bibby (1968, 1974).

4. The data are presented in Appendix G of the report, pp. 267-275. The percentage of all hearing and meeting days devoted to oversight, in what must be a typographical error, is erroneously presented as $1.1 \%$ (p. 268) rather than $11 \%$ in that report. (The raw numbers show 231 days devoted to oversight out of a total of 2,095 days.)

5. The hearings or meetings of formal Joint Committees and those held jointly by House and Senate Committees were also excluded from the analysis. Hearings or meetings of party committees (e.g., steering, policy, and personnel committees) were not included in the data set.

6. I have not yet had the time to analyze these data fully, but one would certainly want to look at such factors as increasing staff resources, larger numbers of liberal Democrats, and changing patterns in committee and subcommittee chairmanships for explanations of the pattern presented in the table.

7. Split partisan control might also be very important as a contextual factor influencing the relationship between other variables and oversight, but one would require data from a period in which the same party controlled the two institutions in order to establish this. Relevant data for the Eighty-Seventh to Ninetyth and the Ninety-Fifth Congresses are now being processed.

8. It is food for thought that on the plane of general activity, staff increases were quite pronounced in the Senate committees between 1973 and 1975, yet overall committee hearings and meetings days actually dropped.

9. Staff has been on the increase for quite some time, although not quite at the recent rate. A longer time frame for the analysis will provide some additional evidence from which to infer the ways in which these variables operate in the Congress.

10. The assumption here is that the larger the number of subcommittees, the more dispersed power is likely to be. This assumption is probably a reasonable one in most cases but there are some potential pitfalls. For example, in a committee with many subcommittees the chairman and a small clique might control the key subcommittees which have jurisdiction over the crucial programs within the committee's jurisdiction.

11. The oversight activity indicator was coded as oversight $=1$, other $=0$.

12. The percentages for the Ninety-Second and Ninety-Third Congresses were $35.5 \%$ and $29.0 \%$, respectively.

13. The House Government Operations Committee, I should note as supplementary evidence, was below the average of oversight units in its oversight efforts, although not as low as in the Senate. 


\section{REFERENCES}

BIBBY, J. F. (1974) “Oversight —Congress' neglected function: will Watergate make a difference?" Presented at the $\mathbf{1 9 7 4}$ Meeting of the Western Political Science Association.

___ (1968) "Congress' neglected function," pp. 477-488 in M. Laird (ed.) Republican Papers. New York: Praeger.

HARRIS, J. (1964) Congressional Control of Administration. Washington, DC: Brookings Institution.

OGUL, M. (1976) Congress Oversees the Bureaucracy. Pittsburgh: Univ. of Pittsburgh Press.

ORNSTEIN, N. J. (1975) "Causes and consequences of congressional change: subcommittee reforms in the House of Representatives, 1970-73," in N. J. Ornstein (ed.) Congress in Change: Evolution and Reform. New York: Praeger.

SCHER, S. (1963) "Conditions for legislative control." J. of Politics (August): 526-661.

SCHICK, A. (1976) "Evaluating evaluation: a congressional perspective," pp. 341-354 in Legislative Oversight and Program Evaluation. Washington, DC: Government Printing Office.

SINGER, J. W. (1978) “Labor and Congress - new isn't necessarily better." National J. (March): 351-353.

U.S. Congress, Commission on the Operation of the Senate (1976) Interim Report of the Commission on the Operation of the Senate, Senate Document, Ninety-Fourth Congress, 2nd session.

U.S. Congress, House Select Committee on Committees (Bolling Committee), Committee Reform Amendments of 1974, Report to Accompany House Resolution 988, NinetyThird Congress, 2nd session, House Report 93-916, Part II.

U.S. Congress, Senate Temporary Select Committee to Study the Senate Committee System (1976) The Senate Committee System, Committee Print, Ninety-Fourth Congress, 2nd session. 